\title{
CHALLENGES AND SUPPORT FOR THE DEVELOPMENT OF NOVICE TEACHERS' PROFESSIONAL IDENTITIES
}

\author{
Fariza Khalid and Hazrati Husnin \\ Universiti Kebangsaan Malaysia, 43600 Bangi Selangor Malaysia
}

\begin{abstract}
Teaching profession requires teachers to be prepared with skills and knowledge to overcome challenges related to subject matter, students, colleagues and personal matters. In order to become an outstanding teacher, one has to undergo formal as well as informal professional development experiences. This study aims to explore the challenges faced by novice teachers and the sources they turned to in order to resolve these challenges. The research participants were three novice teachers who are currently in their first two years of teaching experience. The data were mainly collected using semi-structured interviews with each participant. With the assistance of NVivo software, the data were coded using a thematic analysis approach. The findings indicate that novice teachers not only struggle with their own lack of skills, but are also burdened with students' negative attitudes and difficulties in the environment in which they work. The main supportive elements found to be helping these teachers in solving their problems are support from senior colleagues and family, and information available on the Internet.
\end{abstract}

\section{KEYWORDS}

Novice Teachers, Professional Development, Professional Identities, Significant Others

\section{INTRODUCTION}

In order to become effective, teachers have to be professionally prepared. Teachers therefore need to experience continuing professional development so as to become more effective (Harris, 2002). For pre-service teachers, teaching practice is one of the key elements in their training (Haigh and Tuck, 1999; Hill and Brodin, 2004). Through pre-service training, student teachers are provided with experience in teaching and learning in and outside the classroom, as well as opportunities to enhance the development of their characters so as to become ethical and professional (Kennedy, 2006). Some past studies have proven that teaching practice helps pre-service teachers to have better discussions with lecturers and mentors, and thus helps pre-service teachers to determine the approaches to use and their implications in teaching (Botha and Reddy, 2011; Agbo, 2003). In addition, teaching practice has been found to help pre-service teachers to enhance those skills related to problem identification, decision making, and the selection of approaches to overcome problems in classroom situations, and has also been found to be incredibly significant in developing pre-service teachers' confidence in themselves (Khalid, 2014). Nevertheless, teachers' professional development is not merely limited to pre-service training. Berliner (1995) views the initial stage of new teachers' professionalism as the critical stage in which novice teachers will face numerous conflicts, responsibilities and tasks. These challenges, according to Seyfarth (2002), may impact the efficiency and commitment of novice teachers. Workplace culture, students' attitudes, teachers' low self-confidence, and subject mastery are among the challenging factors for novice teachers (Nolan \& James, 2004). Day et al. (2007) also report that teachers who are within the first three years of the profession show a high commitment towards their profession; however, students' negative attitudes are the main factor impacting on their self-confidence. Novice teachers have also been found to hold back from asking 'too much' of their seniors so as to maintain their self-esteem (Khalid, 2014; Khalid, 2015). Much research has been done into the development of teachers' professional identities; however, for new teachers, the transition from their learning institution to the real context of work has been given a little focus in past research. This paper aims to explore the challenges faced by the novice teachers and the sources they turn to in order to resolve challenges. 


\section{METHODOLOGY}

This study employed a case study design that involved three female novice teachers who are in their first phase of professional life, i.e. between one to three years of employment (Day et al., 2007). All three participants major in Islamic and Moral Education. Two of them are married, but none has a child. These teachers were posted in three different secondary schools in rural area in Borneo (Sarawak). The data was collected using a semi-structured one-to-one interview during a school holiday. Research data were trancribed and coded using NVivo following a thematic analysis approach (Braun \& Clarke, 2006).

\section{FINDINGS}

This paper aims to explore the challenges faced by the novice teachers and the source they turned to in order to resolve these challenges. Based on the analysis, two main factors were derived: internal factors and external factors. Internal factors covered: (a) teachers' ability to adapt to the new environment, (b) classroom management skills, (c) creative-thinking skills, and (d) family or spouse factors. External factors, on the other hand, covered: (a) students' acceptance, (b) students' motivation, (c) students' performance, and (d) students' different culture. All three participants mentioned their struggle to adapt to the new environment. Seemingly, coming from the Malaysian peninsula and now being in Borneo, where people speak different dialects and live in different tribes, was a challenging new environment for them. For example, one of the participants mentioned:

When I was in my first month here, I was struggling to adapt myself with the whole thing! First, since I am teaching in Sarawak, I could not understand their language, but all the students were speaking in their dialect. Then, it was difficult to get myself accepted ... at least, that is how I felt. (Sara)

Another challenge highlighted by the participants is related to their classroom management skills. Azura, for instance, mentioned that she is still having a problem with her classroom management but she has to accept the conditions. It seems that other senior teachers also encountered such problems. In some cases, students ignored their teachers and would only do their work when they were asked personally. However, having a limitation in mastering the dialect the students used has created a gap between Sara and Azura and their students. To engage the students in learning activities, teachers had to be more creative in selecting or planning appropriate activities during the class sessions. Participants in this study did not deny that having to plan creative activities or learning materials to attract their students' motivation wasn't an easy process, and that they sometimes ran out of creative ideas to conduct fun learning experiences for their students. In addition to the above issues, the participants also mentioned the factor of their families. Two of the three participants were married, and both their husbands were working in Peninsular Malaysia. The distance did not allow them to meet often: the only time when they had the chance to see each other was during school holidays, not even at weekends. The teachers reported that being separated from their spouses impacted upon their motivation, which led to lower productivity. Responses from the participants include:

It was an emotional disturbance really, to have your husband living far from you. I almost quit my job. But he consoled me not to ... we need to be more patient. I really hope to transfer back to the peninsula end of this year. The stress is becoming more when I have problems with the students. (Azura)

Some external factors were also recognized. The first challenge the teachers faced is students' acceptance. These novice teachers were struggling with this. They described the situation of the students not paying respect to them in class. They reported that some students just ignored the teacher, thus making them feel uneasy and rejected. Having to understand the culture of any context is a crucial part of making someone comfortable and at ease. However, being in a new cultural setting that is different from where they come from put these novice teachers in difficult situation. Students' motivation was also cited as one of the challenges these teachers are facing. This situation directly impacted the teachers' levels of motivation in return. Sara explained: 
Many times ... when I was feeling so down. Imagine that I had spent a few days preparing the lesson activities and materials but when I entered the class, the students were not paying attention, they showed less respect to me and sometime they were being rude to me. Then, I couldn't help myself, I preached at them instead! They really ruined the mood! (Sara)

As much as their low motivation, students' low academic performance also had a negative influence on these teachers. This prevented them from teaching what they were supposed to teach. Some of them were in a dilemma. For example:

My students are poor in the subject [Islamic Education]. They can't read Arabic letters, or recite the Holy Qur'an. Perhaps having a limitation in those skills made them less attracted to learn the subject. Knowing that it is almost impossible to cover the syllabus as it is supposed to be covered makes me frustrated. Do we have to teach them all the basics again? (Azura)

\subsection{Sources of Support}

The analysis indicates that there are some sources that significantly contribute to the teachers resolving the challenges they face. These primarily rest on: (a) support from senior teachers, (b) self-awareness, (c) support from family, and (d) technology. All three participants mentioned receiving support from senior teachers. From their seniors, the novice teachers learned about dealing with poor students in an effective way. Among the advice they received was to learn their dialect and use it in the class sessions. According to Sara, students are happier when they head their teachers communicating using their own dialect. Another example of the tips received was not to show their state of demotivation in front of the students. Rather, Damia says that they have to smile and call the names of their students one by one. This approach will make the students believe that their teachers really care about them. Two participants also mentioned how they learned from other teachers about different kinds of activities that suit their students. They also learned that teaching low performing students does not mean following the actual syllabus. The most important thing is to make sure they convey good examples to the students and show their good characters. Apart from support from other teachers, the analysis reveals that these novice teachers also depended on their own selves. All of them mentioned how they made sure to be well-prepared for their lessons. For instance, all three mentioned that they would prepare learning materials such as flash cards, quizzes, or even tokens for their students. They explained how they prepared themselves with more fun stories to be told in their class. Preparation prior to the lesson is important, but reflection after the sessions is also needed. The teachers mentioned the importance of self-reflection. For example, Azura stated:

Starting from last year [during her first year of the profession], I tried to do self-reflection. I asked myself what are the things that I am happy with in my lesson? What else can I improve? Once I did that, it really helped, at least it helped me to be more systematic. I even have my own notebook to write down any new ideas that suddenly sparked in my mind. Because I do not want to miss a thing. (Azura) It was undeniable that being in such a situation - having unsupportive students, being in a different culture, and far from family - put these teachers under pressure.

Family is always a source of inspiration and strength. For these teachers, family plays a significant role for them in maintaining their strength and spirits.

To me, I would say my mum is the one with the most significant support. [Laughs] Well, I am not married yet so ... I don't have a husband. So ... my mum will always be there for me. She flew to Sarawak five times already, just to be by my side. When my mum is with me I feel stronger and more motivated. But I wish that within two years from now I will be able to transfer to Selangor or Melaka [states in Peninsular Malaysia]. (Azura)

Another significant source of support that all these novice teachers cited was the Internet. Access to the Internet was viewed as a necessity for them to get new ideas and examples of different activities that they could adopt in their teaching. Although these teachers were teaching in a rural area, they were lucky to have internet access, particularly using their own mobile data. Two of the teachers also mentioned the use of 
instant messaging services such as WhatsApp and Telegram as a medium for them to obtain ideas, and as a creative way to make their lessons more fun and meaningful. Damia, for example, explained how she benefitted from a Telegram group that gathers Islamic Education teachers from different states:

I think my involvement in a Telegram group that consists of other Islamic Education teachers from different parts of the country helps me with regards to many aspects, but most importantly, I gained a lot of quizzes and exercise questions from the group. They also share past year questions in the group. So normally I will download the questions and do some modifications before using them for my students. (Damia)

The use of WhatsApp as a medium for discussion and exchanging ideas was elaborated by Damia and Azura. They used a WhatsApp group for all teachers teaching Islamic Education in the same school. Using the group, information can be disseminated in a short time. Azura highlighted how she was delighted to have the group:

My head of subject panel used a WhatsApp group as a medium for us to communicate. He even shared documents in the group. He also encourages us to use the group to seek help. It was helpful. (Azura)

\section{DISCUSSSION}

This paper aims to explore the challenges faced by novice teachers and the sources they turned to in order to resolve these challenges. For these novice teachers, the challenges do not only come from their own lack of skills related to classroom management, but also result from factors related to their students. Day et al. (2007) explains that it is normal for novice teachers to struggle with their own skills. In this study, novice teachers are also having difficulties with unmotivated students, who show less respect to them. This situation is difficult for novice teachers, and impacts upon their commitment and self-confidence as a teacher. This finding corroborates Day et al.'s (2007) and Beauchamp \& Thomas's (2009) findings that students significantly influence teachers' professional identities, either positively or negatively. This study's findings further strengthen the literature showing that teachers' personal lives have an impact on the development of their professional identities. These findings show that novice teachers also struggle with their own lack of skills. However, interestingly, none of the teachers in this study mentioned any difficulty in mastering their subject content; rather, they highlighted having difficulties in planning activities for teaching and learning. This might be due to the fact that these teachers are teaching students who are have moderate or weak academic performance. Thus, there was less pressure on the teachers with regards to their proficiency and knowledge in the subject matter. This is also explained by Khalid (2013), who reports how novice teachers in a fully residential school with high performing groups of students were having difficulties in preparing themselves with information on their subjects due to the demands from their students who would occasionally ask 'tough' questions. This research has also found that novice teachers are faced with an experience where they are in a phase of accustoming themselves to their new surroundings (culture, people, way of life, et cetera). Stansbury and Zimmerman (2002) recommend that a mentoring system as a vital element of teachers' professional development. Novice teachers cited their learning from seniors as an important resource for professional development. This approach is similar to the concept of 'apprenticeship', as discussed by Wenger (1998), who developed the community of practice (CoP) approach. Through a CoP approach, novice teachers may learn tremendously and tacitly from other teachers (Khalid, 2014). The findings of this study indicate who are the 'significant others' for novice teachers in supporting the development of their professionalism: more senior teachers, family, and the Internet are the main three resources cited by these teachers. In the era of technology, it is expected that novice teachers would use the Internet to gather information to help support their teaching activities. 


\section{CONCLUSION}

This study promotes an understanding of the struggles faced by novice teachers and how they solve their problems in the teaching and learning processes. Professional development is an ongoing process and should be tacitly experienced by novice teachers in order to build a stronger identity as a teacher. However, it is irrefutable that formal professional development and training are greatly needed. Three main 'significant others' that were found to be supportive factors for novice teachers are colleagues or senior teachers, family, and Internet sources.

\section{REFERENCES}

Agbo S. 2003. A Learning Community Model for Professional Development and Transformational Teacher Education: Linking Teacher Preparation with InService Teacher Learning and School Improvement. In: Preston, D. S. (ed.). The Idea of Education. Amsterdam, NY: Radopi.

Beauchamp, C. \& Thomas, L., 2009. Understanding teacher identity: An overview of issues in the literature and implications for teacher education. Cambridge Journal of Ecucation, 39(2), 175-189.

Berliner, D. C., 1995. Educational psychology: An Australian and New Zealand perspective. John Wiley: Brisbane.

Botha, M. L., \& Reddy, C. P. S. 2011. In-service teachers' perspectives of pre-service teachers' knowledge domains in Science. South African Journal of Education. 31, 257-274.

Braun, V., and Clarke, V. 2006. Using thematic analysis in psychology. Qualitative Research in Psychology, 3 (2), 77-101.

Day, C., Sammons, P., Stobart, G., Kington, A., \& Gu, Q., 2007. Teachers Matter. New York: Open University Press.

Haigh, M., \& Tuck, B. 1999. Assessing student teachers' performance in practicum. Paper presented at the AARE, Melbourne.

Harris, A. 2002. School improvement: What's in it for schools?, London Falmer Press.

Hill, G. and Brodin, K.L. 2004. Physical Education Teachers Perceptions of the Adequecy of Unversity course work in preparation for Teaching. Physical Educator, 61(2), 74-87.

Kennedy, M. M. 2006. Knowledge and vision in teaching. Journal of Teacher Education, 57, 1-7.

Khalid, F. 2013. Understanding teachers' identities in relation to continuing professional development and their participation in online communities of practice in Malaysian Smart Schools. Unpublished Doctoral Thesis. Nottingham: The University of Nottingham.

Khalid, F. 2014. The impact of teaching practice experience in shaping pre-service teachers' professional identities. Mediterranean Journal of Social Science, 5 (20), 1921-1927.

Khalid, F. 2015. The Dimensions of Identities and its Roles in Shaping Teachers' Effectiveness, Mediterranean Journal of Social Science, 6 (3), 306-314.

Miles, M.B., \& Huberman, A. M., 1994. An expanded source book: Qualitative data analysis (2 ${ }^{\text {nd }}$ ed.). Thousand Oaks, CA: Sage.

Nolan, J., 2004. Teacher supervision and evaluation theory into practice. New Jersey: John Wiley \& Sons, Ltd.

Seyfarth , J.T., 2002. Human Resources Management for Effective Schools. 3rd ed. Allyn \& Bacon, Boston.

Stansbury, K., \& Zimmerman, J., 2002. Smart induction programs become lifelines for the beginning teacher. Journal of Staff Development, Fall 2002 (Vol. 23, No.4), hal 11-25. California: Wilmer Sdn. Bhd.

Wenger, E., 1998. Communities of practice: Learning, meaning, and identity. NY: Cambridge University Press. 